\title{
Research on the Integration of Tourism Industry and Real Estate Industry in China
}

\author{
Yutao Sun, Yunxin Fu \\ School of Management, Jinan University, Guangzhou, China \\ Email: Sunyutao@foxmail.com
}

How to cite this paper: Sun, Y.T. and Fu, Y.X. (2018) Research on the Integration of Tourism Industry and Real Estate Industry in China. Modern Economy, 9, 1654-1664. https://doi.org/10.4236/me.2018.910104

Received: September 14, 2018

Accepted: October 16, 2018

Published: October 19, 2018

Copyright $\odot 2018$ by authors and Scientific Research Publishing Inc. This work is licensed under the Creative Commons Attribution International License (CC BY 4.0).

http://creativecommons.org/licenses/by/4.0/

\begin{abstract}
With the vigorous development of the tourism industry and the real estate industry, the new format Tourism Real Estate formed by the integration of the two industries appears in the market. The integration of tourism and real estate in China occurred in the 1980s and 1990s and has developed rapidly in recent years. However, the academic research on this aspect is not systematic and in-depth. Therefore, this paper aims to address the following issues: 1 ) What are the driving forces for the integration? 2) What are the basic conditions of integration? 3) How to achieve a better integration of the two industries?
\end{abstract}

\section{Keywords}

Tourism, Real Estate, Industrial Integration, Tourism Real Estate

\section{Introduction}

Today, with the rapid development of China's economy and the continuous advancement of society, the tourism and real estate industries are constantly emerging. In 2017, there were 5 billion domestic tourists in China (2/3 of the world's population), an increase of $12.8 \%$ over the previous year. Domestic tourism revenue was 4.5661 billion yuan, up 15.9\%, and international tourism revenue was 123.4 billion US dollars, up $2.9 \%$. The real estate industry is also growing rapidly. In 2017, China's annual real estate development investment was 1097.9 billion yuan, an increase of $7.0 \%$ over the previous year. In addition, real estate land reached 115,000 hectares, an increase of 7.2\% [1]. In the rapid development of these two industries, tourism real estate born of industrial integration has become an interesting complex. Tourism and real estate industry as two industries with high added value and strong correlation in the tertiary industry, the tourism real estate born by the combination of the two has become one of 
the typical representatives of industrial integration. At the same time, the development of tourism in China has changed from sightseeing to leisure, which has further promoted the close integration of tourism and real estate. The combination of tourism and real estate is both complementary and reciprocal. On the one hand, tourism has driven the popularity of real estate projects and increased the value of real estate projects. On the other hand, real estate projects have made up for the funding gap of tourism and realized short-term profit. As a fruitful representative of industrial integration, tourism real estate has become an economic complex covering all aspects of real estate, vacation, life, leisure and entertainment.

Although the integration of tourism and real estate in China began to sprout in the 1980s and 1990s and developed rapidly in the 21st century, academic research on tourism real estate has lagged considerably. It was not until 1996 that scholars first proposed tourism real estate in China [2]. At present, the theoretical research on tourism real estate is still scarce, and there are relatively few studies on tourism real estate in China from the perspective of industrial integration. Therefore, this paper will focus on the driving forces and foundations of the integration of tourism and real estate from the perspective of industrial integration, and then analyze the integration path of tourism and real estate with Hainan Island as an example.

\section{Literature Review}

In Europe and the United States and some Asian countries, the research on tourism and real estate industry integration is reflected in the following area: Time share, Time-Sharing Hotel, Resort Real Estate, Recreational Property, Recreational Real Estate and Resort Property. Among them, timeshare is the most frequently used in academic research, and most of the research is centered on timeshare. In developed countries, timeshares start early and develop rapidly, so that the research results are very rich too, including the basic concept definition and type division, timeshare industry development, market analysis, market sales, exchange system, security system, the law, the policy and other aspects. For example, Wallace Hobson (2002) studied timeshare products as a second home, including the concept, characteristics, positioning, pricing, etc. of timeshare products [3]; Sampson (2008) proposed that mathematical optimization can be used to improve the effectiveness of the timeshare vacation exchange system [4]. The research cases are mainly aimed at developed countries. In recent years, a group of scholars have begun to study the timeshare market in Latin America and India [5].

In China, Chen (1996) first discussed the related issues of tourism real estate development and proposed three modes of regional tourism real estate development: free mode, planningmode and hybridmode; then Qian (1997) proposed the planning ideas of tourism real estate development from the perspective of system engineering [6], which emphasizes the development of tourism real estate, requires the government and enterprises to develop and plan together with 
various departments, systems and professionals; Shen F (2001) through the development of relevant fields at home and abroad, pointed out that tourism real estate will become a market with enormous development potentiality in China [7]; Cao (2002) analyzed the internal and external conditions of Hainan's development of tourism real estate and pointed out the significance of tourism real estate industry to Hainan's social and economic development [8]; Zhou \& Huang (2007) took Shenzhen OCT tourism real estate as an example, and proposed the business model, theme positioning, development method, investment timing, risk aversion, site selection, capital operation, and product portfolio to tourism real estate investment success [9]; Wu \& Xu (2010) proposed the Tourism-oriented Land Development model (TOLD), and its operation is embodied by four basic features, characterized by special theme, various activities, mixed market, hinterland-depended, recreation-oriented and real estate-supported high amount of investment [10]; Ma \& Wang (2011) analyzed the investment strategy of tourism real estate from the perspective of the full value chain [11].

In summary, most of the existing researches are on the development and management model of tourism real estate after the integration of tourism and real estate, but lack of research from the perspective of how to achieve a better industrial integration of tourism and real estate.

\section{The Driving Forces for the Integration}

Different scholars have different focuses on the research on the driving force of industrial integration. Japanese economist Masu Uekus believes that industrial integration stems from technological progress and regulatory relaxation [12]. American scholar Yoffie discovered through research on the phenomenon of information industry integration that technology development, government relaxation regulation and management innovation are the three most important driving forces for industrial integration [13]. Chinese scholar Wang believes that in addition to macro factors, market factors are also the driving force for industrial integration [14]. Therefore, this paper constructs a four-driving-force model, including two macro factors-technical innovation and national policies, and two market factors-market demand and market competition (as shown in Figure 1). The model will be specifically analyzed below.

\subsection{Huge Market Demand}

On the one hand, as China's tourism development shifts from sightseeing to leisure and holiday-making travel, people are constantly pursuing a tourism demand that integrates comprehensive functions such as sightseeing, leisure, vacation, exhibition, sports, entertainment, health, education and residence. On the other hand, people nowadays pay more attention to the improvement of the living environment, which is not only satisfied with the first residence, but also the second one. Leaving the habitual residence to go to the second residence to spend the weekend and holidays has become a new market demand of the real 




Figure 1. Driving force model for the integration of tourism and real estate.

estate industry. Therefore, the improvement of people's living standards and the upgrading of lifestyles have brought a huge market demand, which greatly promoted the industrial integration of tourism and real estate.

\subsection{Competition between Enterprises}

According to the theory of industrial division, the real estate industry and tourism industry in the upstream industrial tree of tourism real estate are mature industries. The enterprises in these mature industries tend to be saturated in their markets, and the profit of products tends to stabilize or begin to decline. This status quo makes enterprises have a strong desire for production transfer, and a large number of enterprises have begun to open up new fields. In the process of pursuing new paths and new fields, the real estate industry and the tourism industry have explored this intersection of complementary advantages and mutual benefit, namely tourism real estate. This kind of stimulus from the competition in the original industry has become one of the driving forces for the integration of the two industries.

\subsection{Technological Innovation}

With the development of science and technology, technological innovation has also emerged in the tourism and real estate industries. Since the tourism industry and the real estate industry have commonalities in environmental creation, they are consistent in terms of aesthetics, comfort, and convenience, so that they have no obstacles in technology integration. In recent years, advances in new building materials, energy-saving technologies, environmental technologies, network information management technologies, VR, Internet of Things, AI and other technologies have improved the grade and added value of tourism and real estate projects, and constantly promote the integration of the two industries into high-end products. In consequence, technological innovation has become a strong pull and internal driving force for industrial integration.

\subsection{National Policies}

The introduction of relevant national policies has provided support for the bet- 
ter integration of tourism and real estate. From the perspective of tourism, the National Tourism Leisure Program (2013-2020) promulgated by the State Council in 2013 provided policy encouragement for tourism development [15]. In 2014, Several Opinions on Promoting Tourism Reform and Development promulgated by the State Council clarified the key tasks of tourism reform and development, which emphasized the importance of expanding the space for tourism development; In 2015, the Ministry of Land and Resources, the Ministry of Housing and Urban-Rural Development and the National Tourism Administration jointly issued a "Several Opinions on Promoting the Reform and Development of Tourism", which once again clarified the land use policy for new tourism formats.

From the perspective of real estate, in 2016, the Ministry of Finance, the State Administration of Taxation and the Ministry of Housing and Urban-Rural Development jointly issued the "Notice on Adjusting the Preferential Tax Policies for the Deed Tax Business Tax on Real Estate Transactions", which stipulates the latest real estate deed tax policy (except Beijing, Shanghai, Guangzhou and Shenzhen), since 2016. From February 22nd, tax concessions for home purchases are available.

Under the joint action of the above four driving forces, the tourism industry and real estate industry with strong correlation and high added value will be merged to form a new industrial mode-tourism real estate.

\section{The Basic Conditions of the Integration}

The tourism industry and the real estate industry are actually relying on the land. They are the tertiary industry that meets the needs of human beings through the development and utilization of landscape cultural resources. The integration of the two major industries does not occur from the very beginning, but is a natural choice in their respective development processes, so the basis for the integration of the two is also unified. This paper summarizes the basics of the integration of these two industries into the following five aspects.

\subsection{Economic Basis}

Real estate industry and tourism industry, as an important industry of national fiscal revenue, have a significant effect on the local regional economy, but the mode of economic action is slightly different [16]. In the development of land, real estate development is a short-term development activity. The investment is large and the funds are returned quickly. The capital cage can be realized in one year. However, due to the macro policy, the land and financial resources are subject to certain restrictions. Tourism industry is a medium- and long-term investment behavior with relatively few investments. Generally, it needs to be profitable in five to ten years. However, due to the relatively large economic relevance of the tourism industry, it has received considerable support in land and policies. Under the mobilization of economic factors, a land development 
project started with tourism and closed with real estate, which became the basis for the integration of the two industries.

\subsection{Industrial Foundation}

The tourism industry and the real estate industry are two industries with strong correlations in the tertiary industry, both of which have a strong industrial base. On the one hand, the development of the real estate industry can promote the development of the construction industry, building materials industry, financial and insurance industries, and the construction industry and building materials industry are closely related to dozens of industrial sectors such as steel, machinery and oil; on the other hand, tourism The development of the industry stimulates and promotes the development of transportation, catering, accommodation, commerce, agriculture and other industries, as well as the construction of hotels, scenic spots and other places of entertainment and rest in the construction industry. It can be seen that the real estate industry and the tourism industry are prone to generate a considerable overlap in the rapid development, which constitutes the industrial foundation of the integration of the two.

\subsection{Resource Basis}

The resource base is reflected in three aspects: First, environmental resources. As mentioned above, the tourism industry and the real estate industry are all based on environmental transformation, beautiful scenery and good ecological environment, or man-made theme parks, etc., which are environmental resources shared by the tourism industry and the real estate industry. Second, technology Resources. From the perspective of environmental transformation, technologies such as tourism and real estate landscape design, theme positioning, and recreation design can be shared and used. Third, cultural resources. On the one hand, culture is the soul of tourism. The development of tourism areas is inseparable from the excavation and continuation of contexts, or the creation of new experiences in new cultures. On the other hand, the real estate industry, which has been tainted by tourism culture, needs to be shaped. Develop your own culture of residence. The agglomeration of the above three resources has become one of the resource bases of the tourism and real estate industries.

\subsection{Market Foundation}

The real estate industry and the tourism industry are industries that are highly related to market demand, and market demand has become the key to the link between the real estate and tourism markets. The two industries themselves overlap in market positioning. For example, leisure vacationers are the target of tourism and real estate sales, and overlapping markets provide the basis for the integration of tourism and real estate. The development of tourism can create more real estate business opportunities, and the development of real estate can also improve the tourism infrastructure. The effective cooperation between the 
two industries has increased the added value of both parties and broadened the development after industrial integration. Sharing the market and complementing each other.

\subsection{Fund Basis}

As a fusion product of tourism and real estate, tourism real estate inherits the large scale of real estate project development, large investment, and inherits the long-term profit cycle of tourism industry. Its capital recovery cycle may be longer and the capital pressure is relatively large. Therefore, some scholars have pointed out that tourism real estate developers must have two conditions for the development of tourism real estate [17], one must have strong financial strength, sufficient funds to ensure the completion of the previous development, and second, the funds must be guaranteed to be longer. Time is unblocked to ensure the safety of the capital chain, thus ensuring the normal continuity of project management.

\section{The Way to the Integration}

Chinese scholars have two representative approaches to the path of industrial integration from the perspective of tourism: one is the three paths proposed by Xiao and Zheng (2011), namely R \& D design, production management and market development, and pointed out tourism real estate belongs to the market development path [18]; the other is the four paths proposed by Ma et al. (2010), namely resource integration, technology integration, market integration and function integration, and points out that tourism real estate belongs to the market integration path [19]. Therefore, this article will use the market path as one of the paths of analysis.

In order to refine the research, this paper will select Hainan Island's tourism real estate as an example for analysis. In the research, the author finds that the integration of tourism and real estate industry in Hainan is also evident in the functional integration, so the next step will be to analyze the path of industrial integration from both market and function.

\subsection{Market Integration}

\section{1) Personal and family market}

The families who come to Hainan to purchase holiday properties are generally middle and high-level consumers. With the appreciation of land in Hainan and the rise in housing prices, the sales price of tourism real estate will also become higher and higher. Tourism real estate development enterprises must take considerate these objective situations and development trends, locate high-income groups, and study the individualized requirements of high-income people for tourism real estate, so as to achieve the company's profit target. In addition, with the changes in the situation, the original consumer groups are senior government civil servants, state-owned enterprise executives, and celebrities in the film 
and television industry. Now, due to anti-corruption and other reasons, the purchasing power of some government civil servants and state-owned enterprise executives has been diluted, so the island's tourism real estate developers Market targets should focus on private entrepreneurs, corporate executives, high-income intellectuals, and retired wealthy people.

\section{2) Business enterprise customer market}

One of the functions of tourism real estate is to provide a venue for large-scale enterprise training, leisure, business relationship, and employee incentive travel. For example, Hainan Qionghai Boao Jinwan Project and Xinhua Life Insurance Co., Ltd. have cooperated with each other to develop a Xinhua Homeland Hainan Bo'ao Health Project with 2700 sets of health-care residential houses and supporting health facilities [20]. This is worth learning from other tourism real estate developers. In order to expand market share, Hainan's tourism real estate market can be oriented to some large enterprises, implementing more precise positioning, designing and developing tourism real estate according to the needs of enterprises. For example, some large-scale enterprises have regular training and rewards for employees, etc., which can attract custom apartments and villas in Hainan. Business enterprise customers have a wide coverage, such as education, banking, securities, technology, etc., which can become customers of tourism real estate.

\section{3) Out-of-province and overseas markets}

As the only tropical island resort in mainland China, Hainan's tourism industry is favored by the three north regions of Northeast China, Beijing and Northwest China. Among them, the people of Northeast China have become the main immigrants of Hainan Island. Winter is the peak season for Hainan holiday [21]. Migratory bird-type tourists have migrated from all over the country. Such groups have become an important target of Hainan's tourism real estate market. This is a highly integrated and concentrated representation of the two major industrial markets of real estate and tourism. In addition, Hainan is China's third largest hometown of overseas Chinese, and overseas Chinese are also important consumer markets that tourism and real estate companies cannot ignore. In addition, foreign tourists in Hainan are mainly based on the Russian people, and tourists from this country are also potential consumers of Hainan tourism real estate. Therefore, the Hainan tourism real estate market should firmly grasp the target customers from other provinces and overseas countries.

\subsection{Functional Integration}

\section{1) Health and wellness function}

The tourism industry advocates health and wellness functions, while the real estate industry provides comfortable and comfortable accommodations, which are functionally compatible. As the largest tropical island in the country, Hainan has the advantages of health and wellness in terms of natural conditions and policy conditions. From the perspective of Hainan's location and natural condi- 
tions, tourism real estate that combines the functions of old-age care and tourism is one of the best choices. For example, the Gongheyuan project in Haikou city is mainly aimed at the elderly health-care customer group [22]. The Bo'ao town of Qionghai city regards old-age care as the focus of tourism real estate promotion. Hainan has good leisure and holiday resources and climate characteristics suitable for the elderly. It is also a resort for all young people to relax. The integration of health and old-age functions is an important way to enrich the form of tourism real estate.

\section{2) Cultural function}

Culture is the fulcrum of tourism development and the cornerstone of the real estate industry's added value. Tourism real estate must rely on the development of local existing characteristic culture or artificial "specific conception" creation, so that regional brands can demonstrate cultural value. This kind of culture must be a whole, implementable, experiential, and sensible, satisfying the use requirements and spiritual needs of the occupants, and letting them experience a strong sense of intimacy and belonging. For example, the local timeshare industry in Hawaii is particularly mature, the most important of which is the Polynesian culture, which is a great addition to the local tourism properties. Hainan itself has rich cultural factors, such as tropical customs, marine culture, fishery culture, Li culture and Miao culture, and Qiongya red culture. These cultural characteristics should be used to integrate tourism real estate projects into Hainan's local historical context and local characteristics.

\section{3) Multi-component function}

According to the principles of "tourism first and then real estate" and "specializing first and then diversifying", combined with the characteristics of various cities and counties in Hainan, to create a scenic theme and resort area, and then extend to real estate and business, forming a diversity tourism real estate System in the whole island. At present, Hainan has been more successful in the Mission Hills Resort in Haikou [23]. With the theme of golf events and hot spring resorts, and the introduction of the film commune, Lan Kwai Fong and duty-free shopping malls, we have successfully created a fusion of food, shelter, travel, purchase and entertainment combination which is worthy of promotion. In the subsequent development of tourism real estate, it can be combined with Hainan's long-term positioning and major projects to build marine theme parks, aerospace theme parks, tropical agricultural theme parks, etc., to form entertainment, leisure, vacation, health, sports, business, food, A complex multi-tourism real estate cluster that resides in one.

In summary, this paper first analyzes the driving forces of the integration of tourism and real estate, and then discusses the basic conditions of integration. Finally, Hainan tourism real estate is taken as an example to discuss the integration of tourism and real estate. In the driving force of the integration of tourism and real estate, the demand for market demand and technological innovation are the main driving forces, and policy support is the catalyst for the development of 
tourism real estate; in the basic conditions of integration, resources, markets and funds are the most basic cornerstone; in the way of integration, this paper takes Hainan's tourism real estate as an example. Because the occurrence and development of Hainan tourism real estate is typical in China, this paper hopes to provide some reference for other cities, at least from the market. In terms of integration with functions. The highlight of this paper is to clarify the problem of how the two industries integrate, and theoretically expand the theory of industrial integration and the theoretical research of the tourism industry and the real estate industry; in practice, it guides the further integration of the tourism industry and the real estate industry. Future research directions can be studied in inland areas, covering the eastern coast of China, northeast, northwest, southwest, and central China, to study more diversified industrial integration models.

\section{Conflicts of Interest}

The authors declare no conflicts of interest regarding the publication of this paper.

\section{References}

[1] National Bureau of Statistics of the People's Republic of China (2017) Statistical Communique of the 2017 National Economic and Social Development of the People's Republic of China. National Bureau of Statistics of the People's Republic of China, Beijing.

[2] Chen, W.D. (1996) Research on Regional Tourism Real Estate Development. Social Scientists, No. 5, 86-90.

[3] Hobson, W. (2002) A Research Report on Private Residence Clubs: A New Concept for Second Home Ownership. International Journal of Hospitality Management, 21, 285-300. https://doi.org/10.1016/S0278-4319(02)00025-7

[4] Sampson, S.E. (2008) Optimization of Vacation Timeshare Scheduling. Operations Research, 56, 1079-1088. https://doi.org/10.1287/opre.1080.0523

[5] Higgins, S. (2013) Developers Look Hard at Latin America. Hotel Management, New York City.

[6] Qian, P.L. (1997) Tourism Real Estate Development Planning. Tourism Science, No. 3, 34-30.

[7] Shen, F. (2001) The Start of Tourism Real Estate. China Business News, Beijing.

[8] Cao, H.Y. (2002) Research on the Feasibility \& Necessity of Developing Tourism Real Estate in Hainan. Social Science Journal of Hainan University, 3, 90-95.

[9] Zhou, W. and Huang, M. (2007) Research on the Investment Strategy of Tourist Real Estate-A Case Study of Shenzhen, Overseas Chinese Town. Building Econo$m y, 1,69-72$.

[10] Wu, B.H. and Xu, X.B. (2010) Tourism-Oriented Land Development (Told): A New Pattern of Tourism-Real Estate Development in China. Tourism Tribune, Beijing.

[11] Ma, Y. and Wang, H.K. (2011) Study on Investment Strategy of China Tourism Real Estate Based on the Whole Value Chain. Commercial Research, Beijing.

[12] Mannari, H., Caves, R.E. and Uekusa, M. (1982) Industrial Organization I. Industrial Organization, New York. 
[13] Yu, Y.G., et al. (2006) Industrial Integration Theory. People's Publishing House, Beijing.

[14] Wang, Y.L. (2008) Application of the Theory of Industry Convergence in the Development Countermeasures of Tourism Real Estate. Journal of Hunan Institute of Humanities and Technology, No. 03, 51-54.

[15] National Tourism Leisure Program (2013) National Tourism Administration of the People's Republic of China.

[16] Zhong, Y.N. (2006) Research on the Combination Model of Tourism and Real Estate Industry. China Real Estate Finance, No. 2, 13-15.

[17] Wang, B. (2007) Research on Tourism Real Estate Development and Planning. Chongqing University, Chongqing.

[18] Xiao, J.Y. and Zheng, X.M. (2011) The Choice of Industrial Convergence in China's Tourism Industry. Macroeconomic Research, No. 12, 72-78.

[19] Ma, X.F., Zhang, S.B. and Long, M.X. (2010) An Analysis on the Ways of Tourism Industrial Convergence. Economic Geography.

[20] Anonymous (2014) The Two Giants Teamed up to Build Hainan's First Health Home. Tencent Real Estate. http://hn.house.qq.com/a/20140429/000049.htm

[21] Tourist Source Statistics. http://tourism.hainan.gov.cn/goverment/govPrePic/govBelowPic1/

[22] Gong He Yuan Nursing Home (2018) http://www.laoren.com/yanglaoyuan/924.shtml

[23] Mission Hills Properties (2018) http://residence.missionhillschina.com/hk.html 